\title{
DIGITAL TWIN IN FOUNDRY INDUSTRY
}

\author{
${ }^{1}$ Michal FRIDRICH, ${ }^{2}$ Ivo ŠPIČKA \\ 1,2VSB - Technical University of Ostrava, Ostrava, Czech Republic, EU, \\ michal.fridrich.st@vsb.cz, ivo.spicka@vsb.cz
}

https://doi.org/10.37904/metal.2021.4295

\begin{abstract}
A virtual foundry can be an opportunity and a tool for solving economically costly problems, which include complex training of employees or prediction of costs for foundry castings. Virtual foundry is the application of the principles of digital twins to the foundry industry. Despite the fact that some companies have already started to create digital twins, this is a complete novelty in the foundry industry. Virtualization has many undeniable advantages, including not only the visualization of the environment, as has been the case in the past, but also the interactivity of the environment and the possibility of calculations from various areas. The aim of this article is to present some of the modern trends of digital twins in connection with Industry 4.0 and also to present two possibilities how to create a virtual foundry. There are several ways to create a virtual foundry. The first option is to use the NavVis M6 scanning device, which is able to photograph the environment not only as a photograph, but also scan the environment as a cluster of points and then convert it to CAD as a 3D model or use the Indoor viewer software application for virtual browsing. The second option is to use a combination of Blender and Unity programs (which are suitable for creating interactive $3 \mathrm{D}$ environments) and the $\mathrm{C}$ \# programming language for modeling metallurgical production units.
\end{abstract}

Keywords: Digital twin, Industry 4.0, Virtualization

\section{INTRODUCTION}

In today's turbulent environment, where it is very important for businesses to remain competitive, companies often consider creating their own digital twin. In the automotive industry, this area is most developed, but for ordinary industrial companies from other sectors, the creation of their own digital twin is limited by many different factors. Specifically in the foundry industry, the area of virtualization or creation of digital twins is applied very little. It is also due to the specifics of the foundry industry. Whether it is the complexity of technology, complexity of operation or diversity of production (combination of serial and non-serial production of castings). The following chapters will define new trends in Industry 4.0 and options for creating a virtual foundry.

\section{CHANGES IN INDUSTRY 4.0 AND IOT}

It has been 10 years since the date of the fourth industrial revolution or industry 4.0 was first mentioned in 2011. The original idea of this concept was to begin the emergence of so-called smart factories, which will use cyber-physical systems. These systems were to replace the simple and repetitive activities of people in order to streamline the entire company process. Over the past time, we can observe the very rapidly growing popularity of Industry 4.0. One piece of evidence of growing popularity may be a search for the keyword "Industry 4.0" in Google Scholar, which found 136 published items in 2011, found 5,300 items by 2015, and currently has more than 95,000 items. The goal of Industry 4.0 is continuously improve production processes through a high degree of digitization while realizing key business factors such as just in time ordering and receiving material, monitoring business processes by various stakeholders (from customers to managers) and 
predictive maintenance [1]. On July 1, 2016, the project "Basic System Industry 4.0" (BaSys 4.0) was launched, funded by the Federal Ministry of Education and Research of the Federal Republic of Germany. This project is used to build an information system, thanks to which it will be possible to adapt the entire production to rapid changes. For example, when introducing the production of a new product, it will not be necessary to stop the entire production and reorganize the company, but to perform all the necessary actions "on the fly". BaSys 4.0 has already acquired many key industry partners, such as Bosch, ABB and the SMS Group, which are investing heavily in Industry 4.0 to rapidly reduce operating costs and increase overall revenues [2].

The ubiquitous wireless communication and convergence of technologies have enabled the emergence of loT - the Internet of Things, which is an integral part of Industry 4.0 and the digital twin field.

\subsection{Internet of Things}

The number of devices that are connected to the Internet is growing at an unprecedented rate. Globally, 127 devices per second connect to the Internet that do not need a human intermediary to communicate with each other. More and more companies are embracing the digital transformation, and as a result, the world is experiencing a really large increase in the devices that are connected to the Internet of Things. These facilities have a wide range of uses, including energy and waste management systems, noise monitoring, temperature monitoring and NFC payments [3]. Table 1 shows a comparison of the number of facilities in previous years and a prediction of the number of devices in the future.

Table 1 Number of loT devices in the past and future. Own study according to [4].

\begin{tabular}{|c|c|}
\hline Year & Number of loT devices (in billions) \\
\hline 2018 & 7 \\
\hline 2019 & 26.6 \\
\hline 2020 & 31 \\
\hline 2021 & 35 \\
\hline 2022 & 42 \\
\hline 2025 & 75 \\
\hline
\end{tabular}

The total size of the loT market should reach 26 trillion Czech crowns in 2026, and to some extent more than $93 \%$ of companies will use loT technology.

\section{BENEFITS OF DIGITAL TWIN IN FOUNDRY INDUSTRY}

One of the many advantages of the digital twin of a real foundry is the possibility of training new employees without the need for the presence of an inexperienced employee in the often dirty and dangerous operation. Another advantage is the possibility of connecting real sensors to a virtual foundry. Thanks to data mining tools, it is possible, for example, to create formulas for calculating the consumption of heating medium, which is very advantageous for non-series production of castings [5]. Virtualization has many undeniable economic advantages, including not only the visualization of the environment, as has been the case in the past, but also the interactivity of the environment and the possibility of computations in various areas. To obtain the highest value from digital twins, the enterprise must address the digital ethics issues raised by different parties interacting with the data from not just the enterprise, but also its partners and customers. This will require the enterprise to think about the value of the data and its contributions to the business and partners, and also to identify potential areas where its customers or its own data could drive value but also could be at risk [6]. 


\subsection{Predictive maintenance in foundries}

The repeated wear and tear of industrial foundry systems, which arises from normal use, over time and also the effects of the environment, leads to accidental failures, despite the fact that they are designed with high quality. Cutting tools are subject to cumulative wear, hydrocarbon pipes are subject to corrosion, hydraulic structures are subject to erosion, and turbopumps that inject water into the equipment are often exposed to fatigue cracks. The failure of such systems causes damage not only to the foundry industry itself, but also to the environment. Of the existing solutions, predictive maintenance (PdM) seems to be the most suitable. It uses the collected status monitoring data to predict the future state of the system in real time and, based on this knowledge, enables maintenance decisions. As such, PdM allows you to save resources by performing the right and timely actions only when needed. This clear advantage, together with the expansion of computer monitoring technologies, has supported the rapid development of PdM models for constantly worn systems over the last two decades. PdM modeling basically involves four related steps [7]:

- Continuous degradation modeling,

- modeling of maintenance effects,

- development of maintenance principles,

- $\quad$ performance evaluation.

To maintain competitiveness, predictive maintenance should become part of any integrated system, including its deployment in the digital twin of a real foundry. The following text shows two options for creating a virtual foundry according to authors previous research.

\section{SCANNING A REAL FACTORY USING NAVVIS M6}

The NavVis M6 internal mobile mapping system provides fast all-in-one mobile scanning. It captures its surroundings in full 360 degrees, both with photographs and so-called cluster points. The M6 is designed primarily for large-scale scanning projects where data quality is important. It can scan up to 30 times faster than stationary scanners and devices (motion is equal to the walking speed of the device operator) and capture up to 30,000 square meters per day and adapt to complex indoor environments. One operator is enough to assemble and disassemble the device, which facilitates transport. During mapping, you can adjust the height or hide the bikes inside as the corridors narrow or the ceilings drop. From start to finish, capturing reality with NavVis M6 is a hassle-free process. The data is stored on a removable solid state drive, can be easily transferred to workstations and processed using NavVis Sitemaker software. Data can be published in NavVis IndoorViewer or imported as a 3D model into CAD software. In the first case, it is possible to browse the environment on a computer or other smart device in a similar way as in Street View from Google Maps. In the second case, the environment can be browsed in CAD just like any other 3D object. The internal mobile map system NavVis M6 is shown in Figure 1.

Figure 1 Internal mobile maping system NavVis M6 [8]

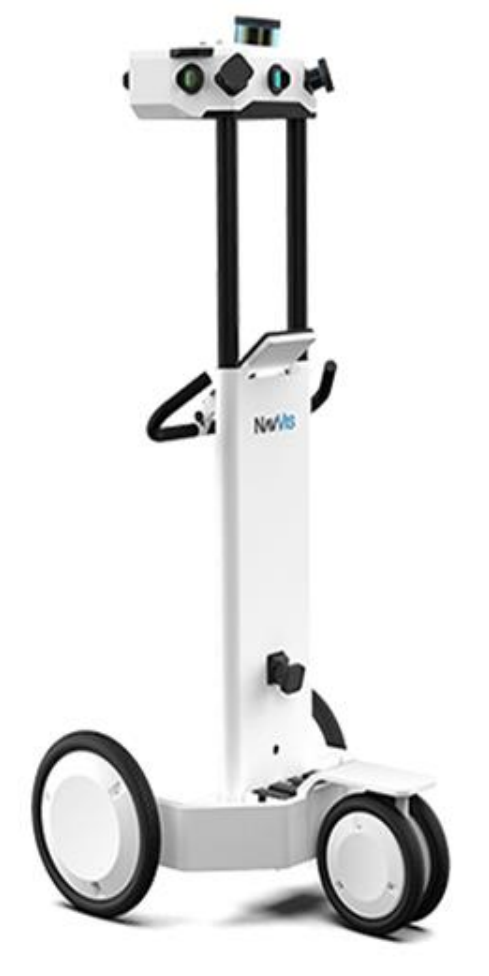


The M6 scanner uses SLAM anchors (accuracy of simultaneous localization and mapping) technology. SLAM is a technology originally developed primarily for the robotic industry, but is now increasingly used in geodesy and autonomous control technologies. SLAM solves a fundamental problem that has long plagued robotic engineers by allowing a device to determine its location while mapping an unknown environment by constantly performing the millions of measurements that underlie trajectory estimation [8]. Figure 2 shows the finished $3 \mathrm{D}$ model of the building created by the M6 device and the additional programming of the properties of some objects.

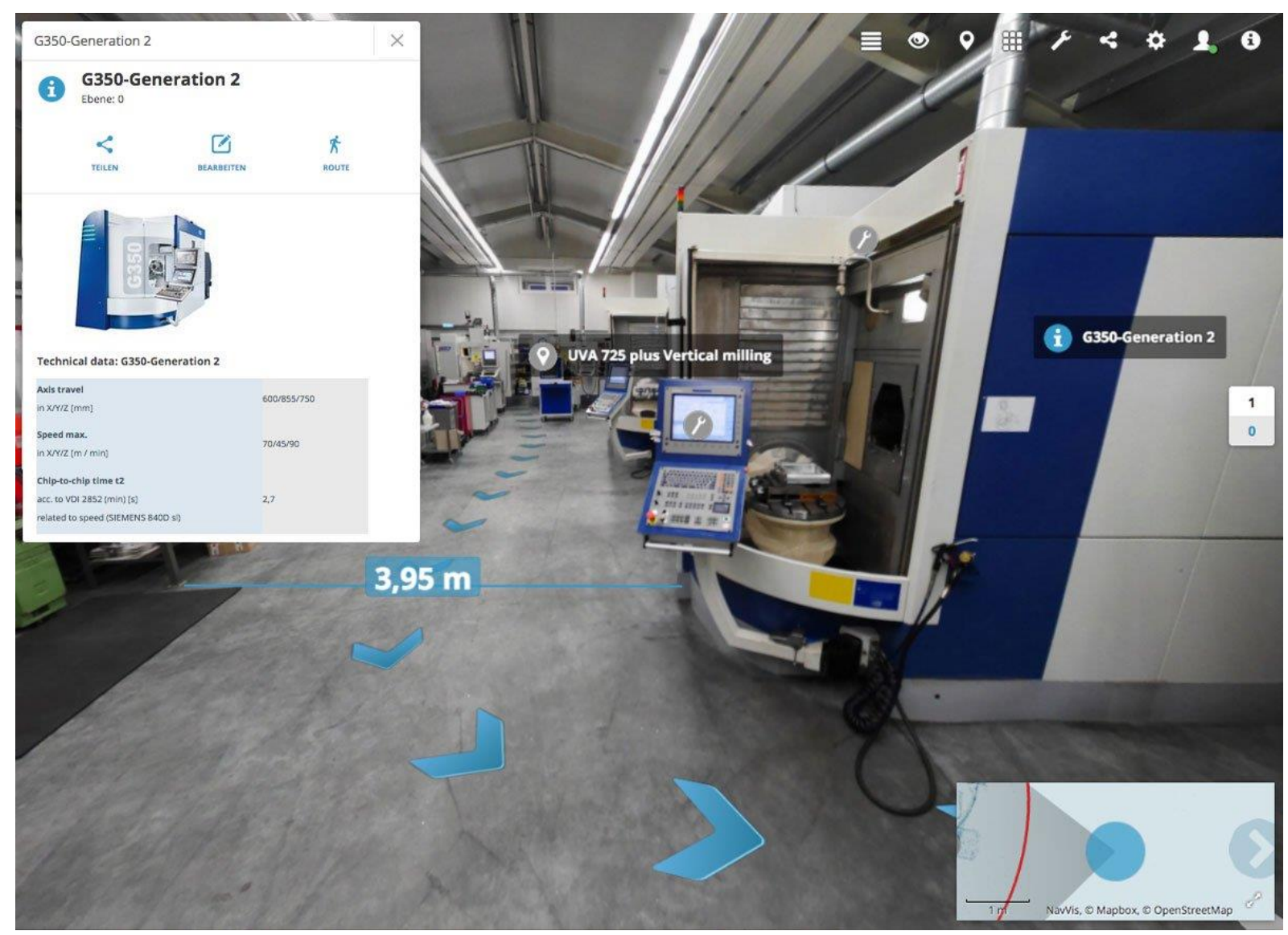

Figure 2 3D model of a building created by the M6 device [8]

Despite the fact that the device is a great novelty, it is becoming more and more affordable. It is already offered for rent in the Czech Republic and Slovakia by two companies.

\section{CREATION OF A VIRTUAL FOUNDRY USING A COMBINATION OF BLENDER, UNITY AND C \# PROGRAMMING LANGUAGE}

Blender is a free, open-source software application designed for creating 3D models. It supports a full range of $3 \mathrm{D}$ creation - modeling, animation, simulation, rendering, composition and motion tracking, game creation or video editing. Advanced users use the Blender API for scripting in the Python programming language to customize Blender to their needs, for example by writing code to create specialized tools or other plug-ins.

Blender is cross-platform and can be run on Linux, Windows and Macintosh computers. Its interface uses OpenGL (Open Graphics Library - an industry standard specifying a multiplatform interface for creating computer graphics applications) to ensure a consistent experience. As a community project under the GNU General Public License (GPL), the public is entitled to make changes to the code base, leading to new features, bug fixes, and better usability of the application itself [9]. 
Blender is an excellent software for creating individual models of foundry parts, because thanks to its modeling accuracy it is possible to create a one-to-one image of real components. However, only 3D modeling software is not enough to create an entire virtual foundry. The individual components need to be deployed in a virtual environment and their properties programmed. Software called Unity is suitable for this purpose.

\subsection{Software unity}

Unity is a cross-platform engine (central part of a software product) developed by Unity Technologies. Since 2018, this engine has been extended to support more than 25 platforms, including Windows and Linux. This engine can be used to create two-dimensional or three-dimensional environments, to create virtual and augmented reality environments, or for example by simulations. All elements of the environment can be animated. During its existence, Unity has expanded beyond the video game industry to areas such as the automotive, architecture, engineering and construction industries, as well as filmmaking [10]. The great advantage of Unity is the ability to convert finished models from Blender directly into the scene. The user interface of the Unity software can be seen in Figure 3. In this example, a functional belt conveyor is shown.

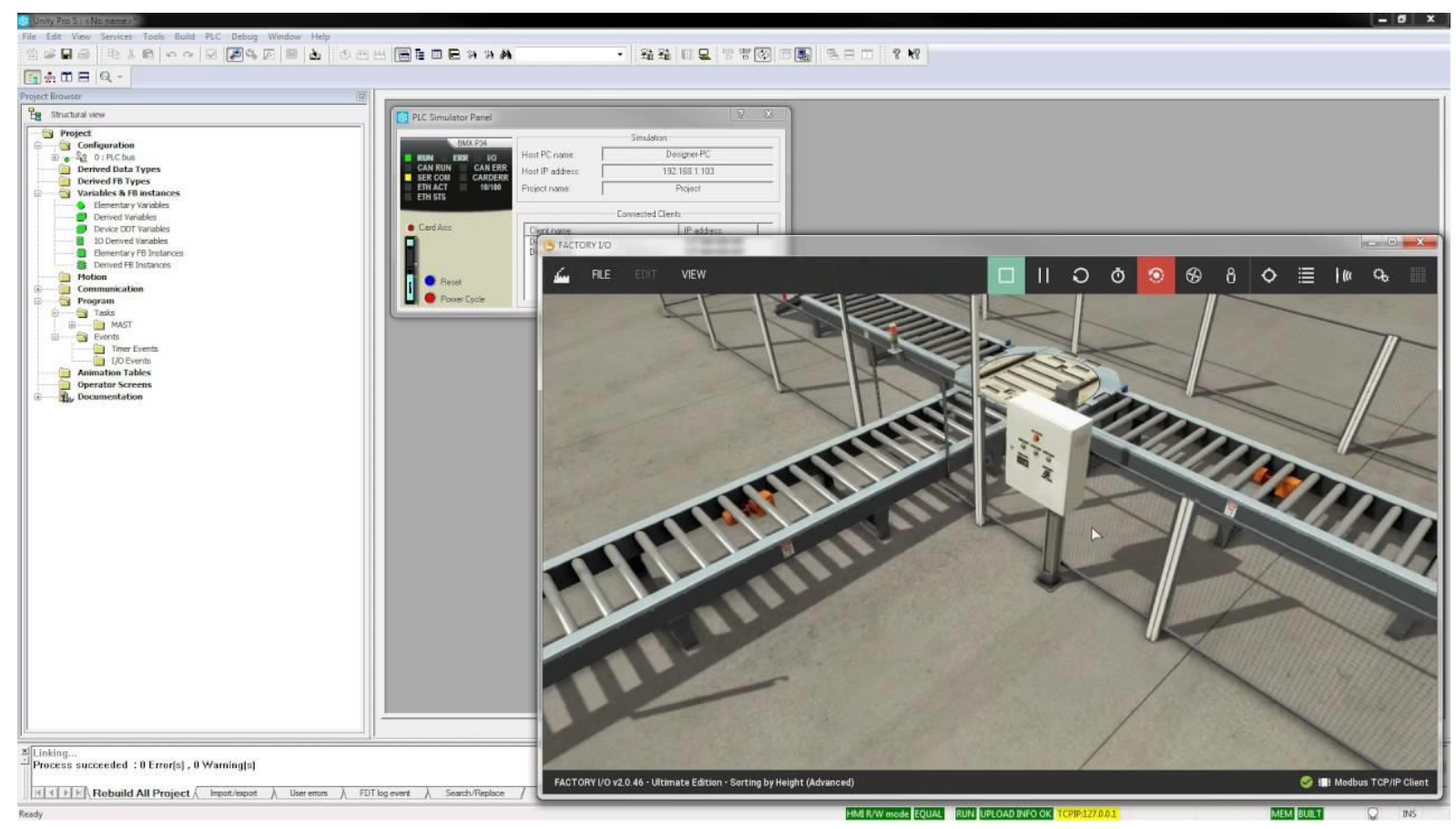

Figure 3 Software Unity user interface [11]

Unity also offers the ability to program individual elements of the scene, most often in the $\mathrm{C}$ \# programming language. Clicking on an object in the scene offers the option to open Microsoft Visual Studio (software for programmers), allowing you to assign an almost unlimited number of properties to the objects, including how they will be linked to each other or how they will respond to user suggestions.

In a functioning virtual foundry, objects could be programmed so that when the user clicks on them, a window lights up and opens a window in which he sees the name of the object, its manufacturer, recommended service period including contact to the service center, warranty expiration date or date from sensors, such as the temperature of the object. As a result, technicians would not have to search for often forgotten paper documentation for equipment in the event of a fault or other event. It would be enough to turn on the virtual foundry application, come to the desired device, click on it and view the required information, all in one place. 


\section{CONCLUSION}

The authors of this article deal with virtualization in foundry, which is the application of the principles of digital twins to the foundry industry. In the previous text, some of the modern trends of digital twins in connection with Industry 4.0 and also two possibilities of how to create a virtual foundry were presented. The advantages of digital twins are indisputable, whether it is the visualization of operation, training of new employees, predictive maintenance or the creation of predictive models. The long-term goal of the authors is to create a digital twin of a real foundry.

\section{ACKNOWLEDGEMENTS}

This article was supported by the specific university researches No. SP 2021/23 and No. SP 2021/71.

\section{REFERENCES}

[1] KUHN, Thomas, ANTONINO, Pablo Oliveira, DAMM, Markus, MORGENSTERN, Andreas, SCHULZ, Dirk ZIESCHE Constantin, MÜLLER Thorsten. Industrie 4.0 Virtual Automation Bus. In: Proceedings of the 40th International Conference on Software Engineering: Companion Proceeedings. [online]. New York, NY, USA: Association for Computing Machinery, 2018, pp. 121-122. ICSE '18. ISBN 978-1-4503-5663-3. Available from: https://doi.org/10.1145/3183440.3195065

[2] NAKAGAWA, Elisa Yumi, ANTONINO, Pablo Oliveira, SCHNICKE, Frank, KUHN, Thomas, LIGGESMEYER, Peter. Continuous Systems and Software Engineering for Industry 4.0: A disruptive view. Information and Software Technology. [online]. 2021, pp. 135, 106562. ISSN 0950-5849. Available from: https://doi.org/10.1016/j.infsof.2021.106562.

[3] 30 Best Internet Of Things Examples In 2021. Jigsaw Academy [online]. [viewed 2021-05-13]. Available from: https://www.jigsawacademy.com/5-best-examples-iot-applications-real-world/.

[4] GILAD MAYAAN, David. The loT Rundown For 2020: Stats, Risks, and Solutions -. Security Today [online]. 13. leden 2020 [viewed 2021-05-06]. Available from: https://securitytoday.com/articles/2020/01/13/the-iotrundown-for-2020.aspx.

[5] FRIDRICH, Michal, SPICKA, Ivo, TYKVA, Tomas. Use of cloud computing tools in virtual foundries. In: 28th International conference on metallurgy and materials (Metal 2019). Brno: TANGER LTD, 2019, pp. 1825-1830. ISBN 978-80-87294-92-5.

[6] PETTEY, Christy. Prepare for the Impact of Digital Twins [online]. [viewed 2021-05-22]. Available from: https://www.gartner.com/smarterwithgartner/prepare-for-the-impact-of-digital-twins/.

[7] HUYNH, K.T. An adaptive predictive maintenance model for repairable deteriorating systems using inverse Gaussian degradation process. Reliability Engineering \& System Safety [online]. 2021, pp. 213, 107695. ISSN 0951-8320. Available from: https://doi.org/10.1016/j.ress.2021.107695.

[8] GMBH, NavVis. NavVis / M6 [online]. [viewed 2019-11-10]. Available from: https://www.navvis.com/m6.

[9] FOUNDATION, Blender. About. blender.org [online]. [viewed 2020-04-30]. Available from: https://www.blender.org/about/.

[10] TECHNOLOGIES, Unity. 2D 3D Game Creator \& Editor / Augmented / Virtual Reality Software / Game Engine / Unity [online]. [viewed 2020-07-24]. Available from: https://unity.com/products/core-platform.

[11] Factory I/O - Documentation [online]. [viewed 2020-04-30]. Available from: https://docs.factoryio.com/. 